\title{
Effectiveness of Photocatalytic Filter for Removing Volatile Organic Compounds in the Heating, Ventilation, and Air Conditioning System
}

\author{
Kuo-Pin Yu, Grace Whei-May Lee, Wei-Ming Huang, Chih-Cheng Wu, and Chia-ling Lou \\ Graduate Institute of Environmental Engineering, National Taiwan University, Taipei, Taiwan, \\ Republic of China \\ Shinhao Yang \\ Department of Leisure and Recreation Management, TOKO University, Chai-Yi County, Taiwan, \\ Republic of China
}

\begin{abstract}
Nowadays, the heating, ventilation, and air conditioning (HVAC) system has been an important facility for maintaining indoor air quality. However, the primary function of typical HVAC systems is to control the temperature and humidity of the supply air. Most indoor air pollutants, such as volatile organic compounds (VOCs), cannot be removed by typical HVAC systems. Thus, some air handling units for removing VOCs should be added in typical HVAC systems. Among all of the air cleaning techniques used to remove indoor VOCs, photocatalytic oxidation is an attractive alternative technique for indoor air purification and deodorization. The objective of this research is to investigate the VOC removal efficiency of the photocatalytic filter in a HVAC system. Toluene and formaldehyde were chosen as the target pollutants. The experiments were conducted in a stainless steel chamber equipped with a simplified HVAC system. A mechanical filter coated with Degussa P25 titania photocatalyst and two commercial photocatalytic filters were used as the photocatalytic filters in this simplified HVAC system. The total air change rates were controlled at $0.5,0.75,1,1.25$, and $1.5 \mathrm{hr}^{-1}$, and the relative humidity (RH) was controlled at $30 \%, 50 \%$, and $70 \%$. The ultraviolet lamp used was a $4-\mathrm{W}$, ultraviolet-C (central wavelength at $254 \mathrm{~nm}$ ) strip light bulb. The first-order decay constant of toluene and formaldehyde found in this study ranged from 0.381 to 1.01 $\mathrm{hr}^{-1}$ under different total air change rates, from 0.34 to $0.433 \mathrm{hr}^{-1}$ under different $\mathrm{RH}$, and from 0.381 to 0.433 $\mathrm{hr}^{-1}$ for different photocatalytic filters.
\end{abstract}

\section{IMPLICATIONS}

Photocatalytic oxidation is a greatly attractive alternative technique for indoor air cleaning. This study introduces photocatalytic oxidation air handling units into the HVAC system to remove the VOCs contaminations. The data, such as the VOC removal efficiency of photocatalytic filter and the clean air delivery rate, provided by this research are useful in real-system application.

\section{INTRODUCTION}

The heating, ventilation, and air conditioning (HVAC) system is a common facility nowadays for maintaining indoor air quality. Air handling units in typical HVAC systems generally contain: (1) outside air intakes, plenums, ducts, and outdoor air; (2) filters and prefilters; (3) heating and cooling coils; (4) chiller and boiler (to supply hot and chilled water for the coils); (5) cooling towers; (6) humidifier or dehumidifier; (7) supply fans; (8) supply ducts; (9) distribution ducts, boxes, and plenums; (10) damper; (11) return air plenums or ducts; (12) return fan; and (13) exhaust outlets. The primary function of typical HVAC systems is to control the temperature (thermal comfort) and relative humidity (RH) of the supply air. The components in a HVAC system that are capable of removing the air pollutants contain the filter and prefilter. The mechanical (or electrostatic) filter is used for the control of the particulates. Some HVAC systems may be equipped with sorbent filters, such as active carbon filter, to remove gaseous contaminates or vapor emitted from the building elements. However, many studies demonstrated that the used filters, which are used to remove particles from the passing air, may pollute the air instead of cleaning it. ${ }^{1,2}$ The filter itself and the captured particulates may act as amplification sites for biological contaminants under high $\mathrm{RH}, 3,4$ and the biological contaminant is one of the important sources of indoor volatile organic compounds (VOCs). The problem with using sorbent filters is the breakthrough of sorbent. When temperature or humidity increases, the adsorbed VOCs may be desorbed and then may re-enter the airstream. After exhausted, the sorbent filters need further treatment, such as regeneration or disposal of the spent sorbent.

Photocatalytic oxidation (PCO) of gas-phase VOCs appears to be a promising alternative process for removing VOCs in HVAC systems. This process is effective in controlling a wide variety of VOCs, including alkanes, alkenes, alcohol, aromatics, chlorinated hydrocarbons, aldehydes, and ketones. ${ }^{5-9}$ Rather than adsorbing VOCs on sorbent, the photocatalytic filter can oxidize VOCs to carbon dioxide $\left(\mathrm{CO}_{2}\right)$ and water $\left(\mathrm{H}_{2} \mathrm{O}\right)$. Furthermore, many studies showed that the PCO process is able to 


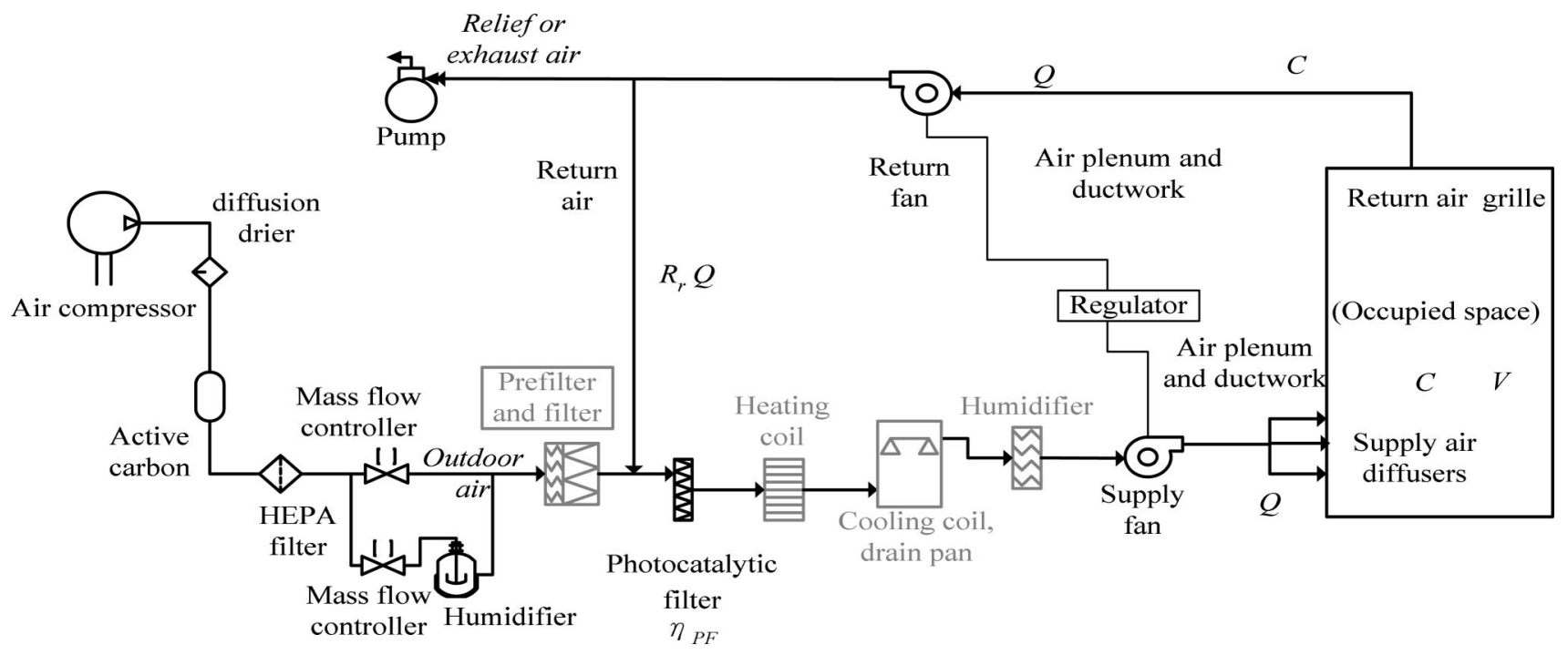

Figure 1. Diagram of the test chamber and the HVAC system.

control the biological contaminations. ${ }^{10-12}$ In this study, we used a small chamber system to investigate the VOC removal efficiency of the photocatalytic filter in the HVAC system. This chamber system includes a stainless steel chamber and a simplified HVAC system. Three types of photocatalytic filters were used in the experiments. The experiments were conducted under different total air change rates and $\mathrm{RH}$ to investigate the effects of these two environmental factors on the VOC removal efficiency. Toluene and formaldehyde were chosen as the target VOCs pollutants. Both toluene and formaldehyde are frequently encountered organic compounds in indoor environments. Toluene can cause irritation to eyes, nose, mucous membrane, and respiratory tract. ${ }^{13-15}$ Exposure to formaldehyde of concentration $\geq 0.25 \mathrm{mg} / \mathrm{m}^{3}$ can cause irritation to eyes, nose, and throat. ${ }^{16}$ Inhaling formaldehyde fumes can result in respiratory tract irritation and impairment of lung function. Formaldehyde has been proven to be a carcinogen, ${ }^{17,18}$ and it may possess reproductive toxicology. According to many gene mutation assays results, exposure to formaldehyde would lead to DNA-protein cross-links and DNA single-strand breaks. ${ }^{19}$ Toluene and formaldehyde were chosen as the surrogates for the six major classes of indoor VOCs (aromatic, aldehyde, alkane, ketone, alcohol, and chlorocarbon) by the American Society of Heating, Refrigerating, and Air-Conditioning Engineers for testing air filtration equipment. ${ }^{20}$

\section{EXPERIMENTAL WORK}

\section{Experimental System}

The experiments were conducted in an $80 \times 80 \times 80 \mathrm{~cm}^{3}$ stainless steel chamber equipped with an HVAC system. To eliminate the confounding effects of other components, this HVAC system was simplified and contained only a duct system (cross-section: $6 \times 6 \mathrm{~cm}^{2}$ ), a supply fan, a return fan, a photocatalytic filter $\left(3.8 \times 3.8 \mathrm{~cm}^{2}\right)$, and an ultraviolet (UV) lamp. Figure 1 shows the diagram of the experimental system.

A mechanical filter coated with Degussa P25 titanium dioxide $\left(\mathrm{TiO}_{2}\right)$ photocatalyst $\left(3.6 \mathrm{mg} \mathrm{TiO} 2 / \mathrm{cm}^{2}\right.$-filter $)$ and two commercial photocatalytic filters were used in the experiments. Degussa P25 $\mathrm{TiO}_{2}$ powder has a primary particle diameter of $30 \mathrm{~nm}$, a surface area of $50 \mathrm{~m}^{2} / \mathrm{g}$ (Brunauer, Emmett, and Teller [BET]), and a crystal structure of $70 \%$ anatase and $30 \%$ rutile. ${ }^{5,6}$ The $\mathrm{TiO}_{2}$ coating procedure was described as follows. ${ }^{8,21,22}$ First, the $\mathrm{TiO}_{2}$ powder was suspended in distilled water by the ultrasonic tank (Branson 5200). Then, the filter was immersed in the $\mathrm{TiO}_{2}$ sludge. After the filter became dry, a $\mathrm{TiO}_{2}$ coating remained on the surface of the filter. The UV lamp used in the experiments was a 4-W, UV-C (central wavelength at $254 \mathrm{~nm}$ ) strip light bulb. This lamp was chosen because the absorbance of $\mathrm{TiO}_{2}$ is greatest at $254 \mathrm{~nm} .{ }^{23}$ The configuration of the photocatalytic filter system is shown in Figure 2. The light flux at the filter surface was measured by the UVX radiometer (Model UVX-36, UVP) at nine points. The result of the measurement is shown in Figure 3 . The ozone concentration in the chamber was monitored continuously by ozone analyzer model 400A (API Inc.).

\section{Mixing Level of the Test Chamber}

To obtain the adequate mixing level (>80\%), a fan was installed in the test chamber. The mixing level of the test chamber was calculated as below:

$$
\eta \%=\left\{1-\frac{\sum_{\mathrm{i}=1}^{\mathrm{n}}\left[\left|C_{\mathrm{tr}}\left(t_{\mathrm{i}}\right)-C_{\mathrm{th}}\left(t_{\mathrm{i}}\right)\right| \times\left(t_{\mathrm{i}}-t_{\mathrm{i}-1}\right)\right]}{\sum_{\mathrm{i}=1}^{\mathrm{n}}\left[C\left(t_{\mathrm{i}}\right) \times\left(t_{\mathrm{i}}-t_{\mathrm{i}-1}\right)\right]}\right\} \times 100 \%
$$

where $\eta(\%)$ is the mixing level, $t_{\mathrm{i}}(\mathrm{hr})$ is the time when the $\mathrm{i}^{\text {th }}$ sample was taken, $n$ is the serial number of the sample, and $C_{\mathrm{tr}}\left(t_{\mathrm{i}} ; \mathrm{ppm}\right)$ is the gaseous tracer $\left(\mathrm{CO}_{2}\right)$ concentration at time $t_{\mathrm{i}}$. $C_{\mathrm{th}}\left(t_{\mathrm{i}} ; \mathrm{ppm}\right)$ is the theoretical tracer concentration under a completely mixing condition, and $C_{\text {th }}\left(t_{\mathrm{i}}\right)$ can be calculated by the following equation: 


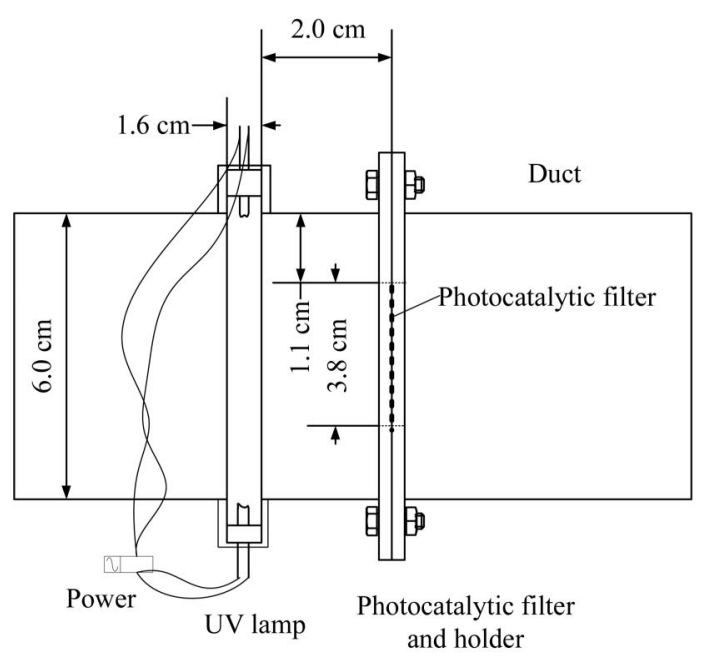

Side View

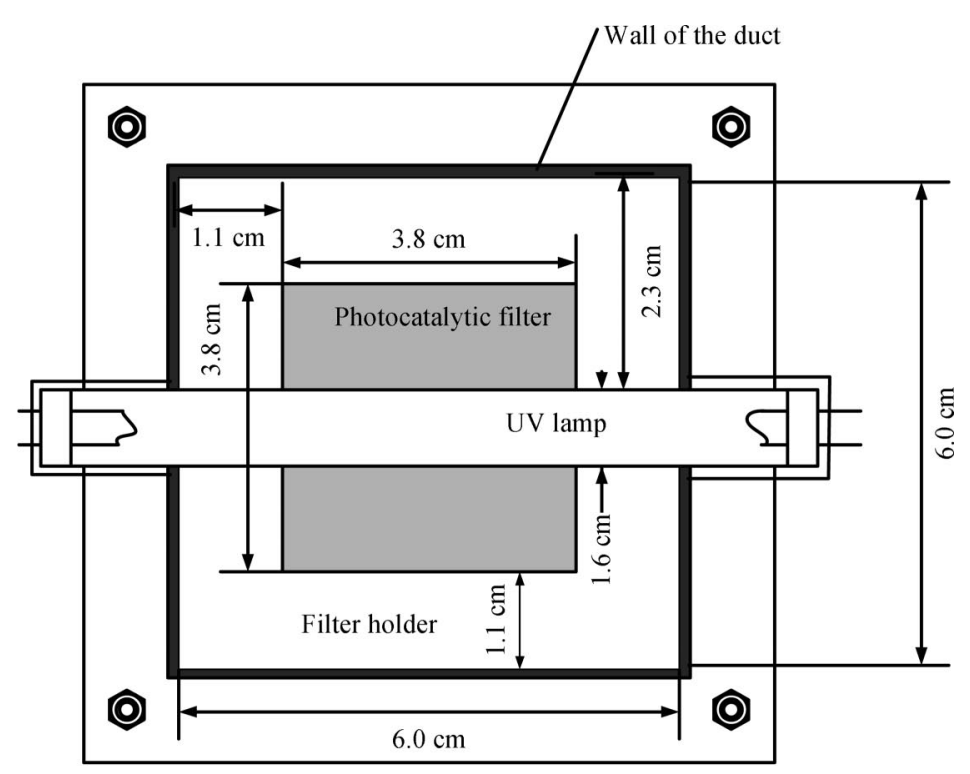

Top View

Figure 2. Configuration of the photocatalytic filter and the UV lamp system.

$$
C_{\mathrm{th}}\left(t_{\mathrm{i}}\right)=C_{\mathrm{tr}}(0) e^{-\mathrm{Ach} \times \mathrm{t}}
$$

in which $C_{\mathrm{tr}}(0)$ is the initial gaseous tracer concentration (ppm), and Ach is the air change rate of the test chamber $\left(\mathrm{hr}^{-1}\right)$. Q-Trak (TSI. 8550) was used to monitor the $\mathrm{CO}_{2}$ concentration continuously.

The mixing levels of test 1 and test 2 were $96.4 \%$ and $96.6 \%$, respectively, as shown in Table 1 .

\section{Sampling and Analysis of VOCs}

Toluene and formaldehyde were chosen as the target VOCs of this study. The sampling apparatus for toluene included 500-mg Tenax TA (60/80 mesh) cartridges (SUPELCO) and a personal sampling pump (SKC). The sampling flow rate was $25 \mathrm{~mL} / \mathrm{min}$, and the sampling time

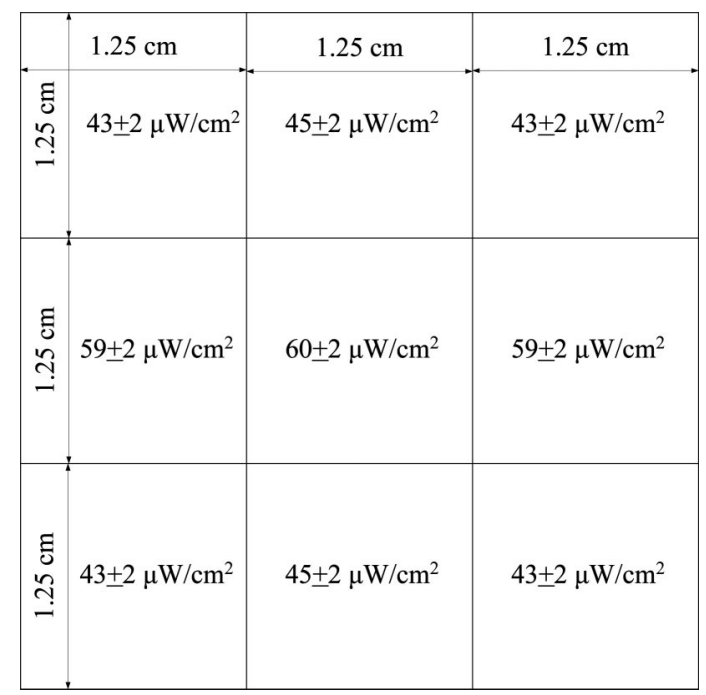

Figure 3. The UV intensity measured at nine points (center of each square) of the filter surface. was 6 min. The cartridges were purged with nitrogen gas (purity: $99.9 \%$, flow rate: $30 \mathrm{~mL} / \mathrm{min}$ ) under $230{ }^{\circ} \mathrm{C}$ for $\sim 2-4$ hr before use.

After sampling, the Tenax TA cartridges were thermal desorbed and cryofocussed by Aero Trap Desorber (TEKMAR 6000) and then analyzed by the gas chromatography (GC) and the flame-ionization detector (HP5890 series II). The quantification was conducted as described. First, we injected $1-\mu \mathrm{L}$ reference solution into a $125-\mathrm{mL}$ glass sampling bulk (SUPELCO). After the reference solution was evaporated, the air in the sampling bulk was flushed out by compressed air at a flow rate of $25 \mathrm{~mL} / \mathrm{min}$, and the tail gas was sampled on a Tenax TA cartridge for $10 \mathrm{~min}$ and then analyzed by the GC system. Based on the analytic results of a series of reference solutions of toluene, a calibration curve was created.

The sampling apparatus for formaldehyde contained LpDNPH S10 air monitoring cartridges (SUPELCO) and a personal sampling pump (SKC). The sampling flow rate was $200 \mathrm{~mL} / \mathrm{min}$, and the sampling volume was $2000 \mathrm{~mL}$. After sampling, the LpDNPH S10 cartridge was eluted with 2-mL aliquots of acetonitrile, and the eluate was collected to the $10-\mathrm{mL}$ mark on a volumetric flask. The extract was analyzed with GC-photoionization detection ([GC-PID] HP5890 series II), and the injected volume was $2 \mu \mathrm{L}$. The quantification was conducted by analyzing a

Table 1. Mixing level of test chamber.

\begin{tabular}{lccccc}
\hline \hline Test & $\begin{array}{c}\text { Initial } \mathbf{C O}_{\mathbf{2}} \\
\text { Concentration } \\
\mathbf{( p p m )}\end{array}$ & $\begin{array}{c}\text { Temperature } \\
\text { ('C) }\end{array}$ & $\begin{array}{c}\mathbf{R H} \\
\mathbf{( \% )}\end{array}$ & $\begin{array}{c}\text { ACH } \\
\mathbf{( h r}^{-\mathbf{1}} \mathbf{)}\end{array}$ & $\begin{array}{c}\text { Mixing Level } \\
(\%)\end{array}$ \\
\hline 1 & 3392 & 25.4 & 66.3 & 1.0 & 96.4 \\
2 & 4438 & 25.9 & 67.4 & 1.0 & 96.6 \\
\hline \hline
\end{tabular}

$\mathrm{ACH}$ indicates air change rate in the test chamber. 
series of reference solutions of formaldehyde with the GC system (HP5890 series II GC-PID). A calibration curve was created based on the analytic result of the reference solutions of formaldehyde.

\section{Experiment Setup}

Before the experiments started, the stainless steel chamber was conditioned for $\sim 6 \mathrm{hr}$ to attain the required experimental conditions. The experiments were conducted under $\mathrm{RH}$ of $30 \%, 50 \%$, and $70 \%$ and total air change rates of $0.5,0.75,1,1.25$, and $1.5 \mathrm{hr}^{-1}$ (recirculation rate is $50 \%$ ). Then, the UV lamp was turned on and warmed up for $15 \mathrm{~min}$. The VOC solvent was injected into the chamber when the condition procedure was finished. After the VOC was completely evaporated, the experiments got started. The outlet air of the chamber was sampled on Tenax TA cartridges (for toluene) or LpDNPH S10 cartridges (for formaldehyde) for every $30 \mathrm{~min}$ and then analyzed by the GC system immediately after sampling. The control experiments were performed in the same way but with the UV lamp off. The experiments were conducted with and without the photocatalytic filter to provide evidence for how much VOC removal was being caused by the photocatalytic filter and how much VOC removal resulted from the direct gas-phase photochemisty.

\section{RESULTS AND DISCUSSION}

\section{Natural Decay and Decay Constant}

In this study, the mass balance of VOCs within the test chamber can be described as the following differential equation:

$$
V \frac{d C}{d t}=Q R_{\mathrm{r}} C\left(1-\eta_{\mathrm{PF}}\right)-Q C
$$

where $V\left(\mathrm{~m}^{3}\right)$ is the volume of the test chamber; $C$ (ppm) is the average VOC concentration in the chamber; $Q$ $\left(\mathrm{m}^{3} \mathrm{hr}\right)$ is the airflow rate passing through the photocatalytic filter; $R_{\mathrm{r}}$ is the recirculation rate (in this study, $R_{\mathrm{r}}=$ $0.5)$; and $\eta_{\mathrm{PF}}$ is the VOC removal efficiency of the photocatalytic filter ( $\eta_{\mathrm{PF}}$ is replaced by $\eta_{\mathrm{UV}}$ when the system is illuminated with no photocatalytic filter present), which can be expressed as the following equation:

$$
\eta_{\mathrm{PF}}=\frac{\left(C_{\mathrm{up}}-C_{\text {down }}\right)}{C_{\mathrm{up}}}
$$

where $C_{\mathrm{up}}\left(=R_{\mathrm{r}} C\right)$ and $C_{\text {down }}(\mathrm{ppm})$ are the upstream and downstream VOC concentrations, respectively. The value of $\eta_{\text {PF }}$ would vary with the VOC concentration if the PCO reaction rate fits the Langmuir-Hinshelwood rate form, which is the most reported rate form for PCO kinetics. ${ }^{5-}$ $7,9,24$ To simplify this problem, it was assumed that the PCO reaction fits the first-order reaction rate form, 8,25 and this assumption was authenticated in the experiments. Thus, the VOC removal efficiency of the photocatalytic filter $\left(\eta_{\mathrm{PF}}\right)$ could be treated as a constant. Consequently, the general solution of eq 3 is:

$$
C=C_{0} \exp \left[-\frac{Q}{V}\left(1+R_{\mathrm{r}} \eta_{\mathrm{PF}}-R_{\mathrm{r}}\right) t\right]
$$

where $C_{0}$ is the initial VOC concentration in the chamber.

In this study, the natural decay constant (Kn) was defined as the first-order decay constant of VOCs concentrations in the chamber when the UV lamp was off. The decay constant $(\mathrm{Ka})$ was defined as the first-order Ka of the VOCs concentration, whereas the photocatalytic filter was illuminated with the UV light. According to eq 5, the $\mathrm{Ka}$ and $\mathrm{Kn}$ are $\mathrm{K}_{\mathrm{a}}=\left(1+R_{\mathrm{r}} \eta_{\mathrm{PF}}-R_{\mathrm{r}}\right) Q / V$ and $\mathrm{K}_{\mathrm{n}}=(1$ $\left.+R_{\mathrm{r}}\right) Q / V$, respectively. The $\mathrm{Ka}$ and $\mathrm{Kn}$ were also used to describe the first-order decay of VOC concentration, when the system is illuminated by UV light without photocatalytic filter present and runs in the dark with no photocatalytic filter present, respectively.

\section{Ka for Real System Application}

The Ka of VOC concentrations developed in this study need to be transferred to more applicable parameters (e.g., clean air delivery rate [CADR] or removal efficiency) before being applied in a real system. The CADR was first defined as the volume of filtrated air delivered by the air cleaners. Here, the CADR represents the volume of filtrated air passing through the photocatalytic filter per unit time, and it can be expressed as the following equation:

$$
\mathrm{CADR}=\left(K_{\mathrm{a}}-K_{\mathrm{n}}\right) V
$$

where CADR is relevant to the VOCs removal efficiency of the photocatalytic filter and the airflow rate passing through the photocatalytic filter. The relationship between the CADR and the VOC removal efficiency of the photocatalytic filter can be described as the following equation:

$$
\mathrm{CADR}=R_{\mathrm{r}} \eta_{\mathrm{PF}} Q=R_{\mathrm{r}} \eta_{\mathrm{PF}} A v
$$

where $A$ is the filtration area of the photocatalytic filter, and $v$ is the face velocity. Dividing eq 7 by the filtration area of the photocatalytic filter:

$$
\frac{\mathrm{CADR}}{A}=R_{\mathrm{r}} \eta_{\mathrm{PF}} v
$$

Equation 8 represents the CADR per unit area (CADR/A) of the photocatalytic filter. This parameter can be applied to evaluate the CADR of an interested real system.

\section{Effect of RH}

Figure 4 shows the Ka of the toluene concentration with photocatalytic filter present under the RH of 30\%, 50\%, and $70 \%$, which represent the dry, medium, and humid environmental conditions, respectively. The Kn under RH of $30 \%, 50 \%$, and $70 \%$ ranged from 0.248 to $0.250 \mathrm{hr}^{-1}$, and the Ka varied from 0.34 to $0.381 \mathrm{hr}^{-1}$. The Ka rose $12.1 \%$, when the RH increased from $30 \%$ to $70 \%$. As shown in Figure 6, the values of the CADR, the CADR/A, 

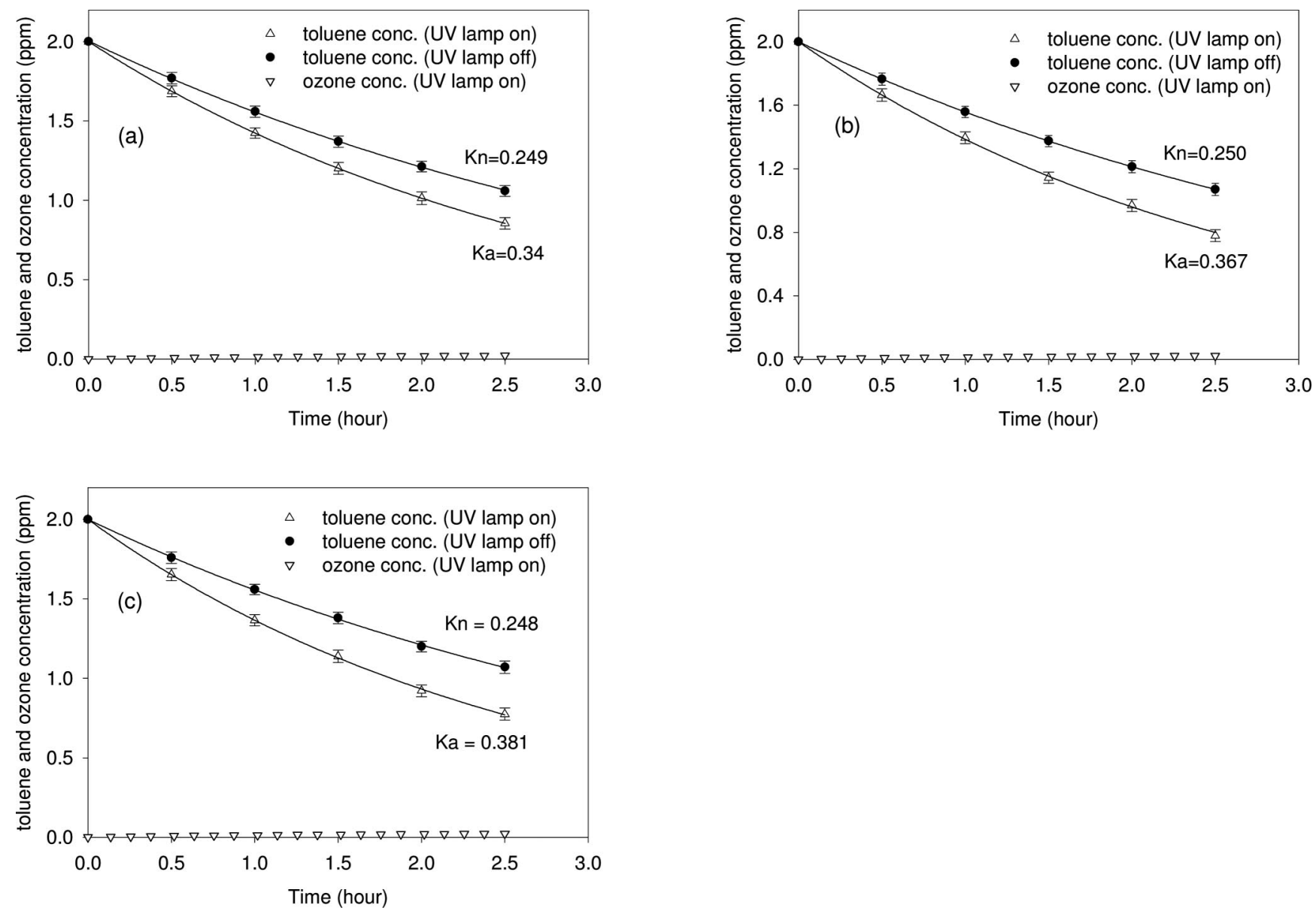

Figure 4. Effect $\mathrm{RH}$ on the $\mathrm{Ka}$ of the toluene concentrations with the photocatalytic filter (a) $\mathrm{RH}=30 \%$, (b) $\mathrm{RH}=50 \%$, and (c) $\mathrm{RH}=70 \%$.

and the $\eta_{\text {PF }}$ for toluene increased with RH. The ozone concentration in the chamber was $<25 \mathrm{ppb}$ and was very close to the background ozone concentration. Under this condition, the toluene-ozone $\left(\mathrm{O}_{3}\right), \mathrm{UV} / \mathrm{O}_{3}$, and $\mathrm{UV} / \mathrm{O}_{3} /$ $\mathrm{TiO}_{2}$ reaction rates were much slower than the $\mathrm{UV} / \mathrm{TiO}{ }_{2}$ reaction rate. Therefore, the toluene removal resulted mainly from the photocatalytic filter $\left(\mathrm{UV} / \mathrm{TiO}_{2}\right)$ instead of from the toluene- $\mathrm{O}_{3}, \mathrm{UV} / \mathrm{O}_{3}$, or $\mathrm{UV} / \mathrm{O}_{3} / \mathrm{TiO}_{2}$ reaction.

Figure 5 shows the Kas of the toluene concentration with no photocatalytic filter present under RH of $30 \%$, $50 \%$, and $70 \%$, respectively. The Kn ranged from 0.248 to $0.249 \mathrm{hr}^{-1}$, and the Ka ranged from 0.260 to $0.263 \mathrm{hr}^{-1}$. The increase of $\mathrm{RH}$ has an insignificant effect on the removal of toluene by UV light. The ozone concentration in the chamber was $<25 \mathrm{ppb}$. Therefore, the toluene- $\mathrm{O}_{3}$, $\mathrm{UV} / \mathrm{O}_{3}$, and $\mathrm{UV} / \mathrm{O}_{3} / \mathrm{TiO}_{2}$ reaction rates were very slow under this condition. The removal of toluene was caused by direct gas-phase photolysis.

As shown in Table 2, the Kn and $\mathrm{Ka}$ of the formaldehyde concentration with photocatalytic filter present under $\mathrm{RH}$ of $30 \%, 50 \%$, and $70 \%$ ranged from 0.247 to 0.249 $\mathrm{hr}^{-1}$ and from 0.421 to $0.433 \mathrm{hr}^{-1}$, respectively. When the $\mathrm{RH}$ increased from $30 \%$ to $70 \%$, the Ka rose $2.85 \%$. The values of the CADR, the CADR/A, and the $\eta_{\mathrm{PF}}$ for formaldehyde also increased with $\mathrm{RH}$, as shown in Figure 6.

The $\mathrm{Ka}$ of the formaldehyde concentration without photocatalytic filter present under $\mathrm{RH}$ of $30 \%, 50 \%$, and
$70 \%$ ranged from 0.247 to $0.248 \mathrm{hr}^{-1}$. When the system was illuminated by UV light, the Ka ranged from 0.315 to $0.316 \mathrm{hr}^{-1}$. The effect of $\mathrm{RH}$ on the formaldehyde removal by UV light was insignificant. The ozone concentration in the chamber was $<25 \mathrm{ppb}$. The toluene- $\mathrm{O}_{3}$, $\mathrm{UV} / \mathrm{O}_{3}$, and $\mathrm{UV} / \mathrm{O}_{3} / \mathrm{TiO}_{2}$ reaction rates were very slow under this condition. The removal of formaldehyde resulted mainly from direct gas-phase photolysis.

The result above demonstrates that the increase of $\mathrm{RH}$ has a positive effect on the effectiveness of the photocatalytic filter for removing toluene and formaldehyde. A possible explanation for this result is that the increase of $\mathrm{RH}$ can enhance the formation of hydroxyl radical. When an electron on the valence band (VB) of photocatalyst absorbs a photon with energy higher than the band gap between the VB and the conduction band (GB), it will be promoted to the GB, and, thus, an electron-hole pair $\left(\mathrm{e}^{-}\right.$ and $\mathrm{h}^{+}$) is created. The water molecule adsorbed on the surface of the photocatalyst will be oxidized to hydroxyl radicals by the holes $\left(\mathrm{h}^{+}\right)$. Hydroxyl radicals are the major free radicals attacking and discomposing VOC molecules. ${ }^{8,22}$

When the RH increased from 30\% to $70 \%$, the values of the CADR, the CADR/A, and the $\eta_{\mathrm{PF}}$ for toluene increased $\sim 46 \%$. However, the values of the CADR, the CADR/A, and the $\eta_{\text {PF }}$ for formaldehyde increased merely $\sim 6.4 \%$. The enhancement effect of RH on the effectiveness of a photocatalytic filter for removing formaldehyde 
Yu, Lee, Huang, Wu, Lou, and Yang
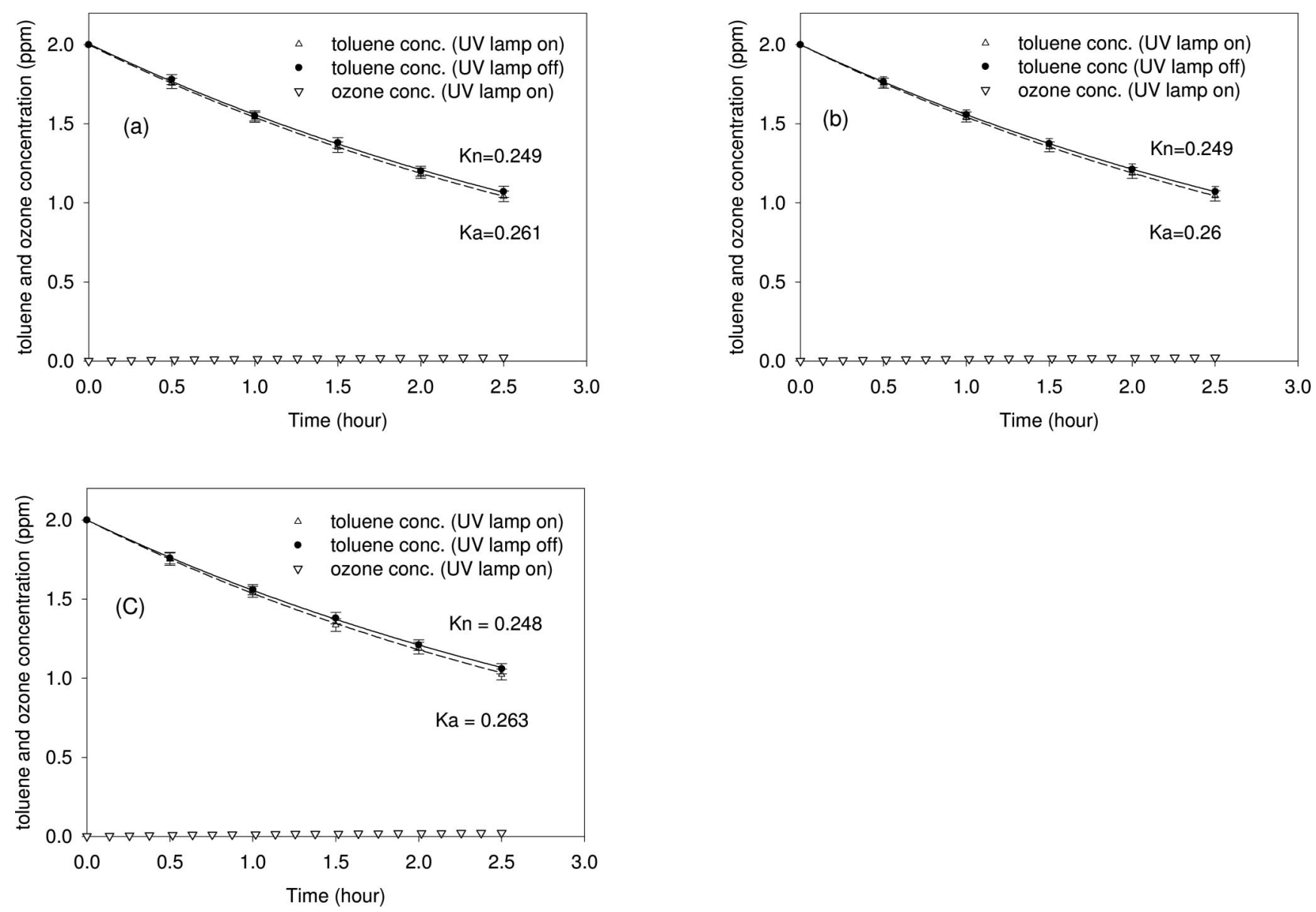

Figure 5. Effect of $\mathrm{RH}$ on the $\mathrm{Ka}$ of the toluene concentrations without the photocatalytic filter (a) $\mathrm{RH}=30 \%$, (b) $\mathrm{RH}=50 \%$, and (c) $\mathrm{RH}=$ $70 \%$.

Table 2. Summary of the experimental conditions, results, and calculated parameters.

\begin{tabular}{|c|c|c|c|c|c|c|c|c|}
\hline VOC & Filter & $\begin{array}{l}\text { RH } \\
\text { (\%) }\end{array}$ & $\begin{array}{c}v \\
(m / h r)\end{array}$ & $\begin{array}{c}\mathbf{K n} \\
\left(\mathrm{hr}^{-1}\right)\end{array}$ & $\begin{array}{c}\mathbf{K a} \\
\left(\mathrm{hr}^{-1}\right)\end{array}$ & $\begin{array}{c}\text { CADR } \\
\left(\mathrm{m}^{3} / \mathrm{hr}\right)\end{array}$ & $\begin{array}{c}\text { CADR/A } \\
\left(\mathrm{m}^{3} / \mathrm{hr} / \mathrm{m}^{2}\right)\end{array}$ & $\eta_{\mathrm{PF}}$ \\
\hline \multirow[t]{3}{*}{ Toluene } & D-type & 30 & 177 & 0.249 & 0.34 & 0.0466 & 32.3 & 0.364 \\
\hline & & 50 & & 0.250 & 0.367 & 0.0599 & 41.5 & 0.468 \\
\hline & & 70 & & 0.248 & 0.381 & 0.0681 & 47.2 & 0.532 \\
\hline \multirow[t]{3}{*}{ Formaldehyde } & D-type & 30 & 177 & 0.248 & 0.421 & 0.0886 & 61.3 & 0.692 \\
\hline & & 50 & & 0.247 & 0.424 & 0.0906 & 62.8 & 0.708 \\
\hline & & 70 & & 0.249 & 0.433 & 0.0942 & 65.2 & 0.736 \\
\hline \multirow[t]{5}{*}{ Toluene } & D-type & 70 & 177 & 0.248 & 0.381 & 0.0681 & 47.2 & 0.532 \\
\hline & & & 266 & 0.374 & 0.553 & 0.0916 & 63.5 & 0.477 \\
\hline & & & 355 & 0.498 & 0.694 & 0.100 & 69.5 & 0.392 \\
\hline & & & 444 & 0.627 & 0.828 & 0.103 & 71.3 & 0.332 \\
\hline & & & 532 & 0.747 & 0.945 & 0.101 & 70.2 & 0.264 \\
\hline \multirow[t]{5}{*}{ Formaldehyde } & & & 177 & 0.249 & 0.433 & 0.0942 & 65.2 & 0.736 \\
\hline & & & 266 & 0.376 & 0.609 & 0.119 & 82.6 & 0.621 \\
\hline & D-type & 70 & 355 & 0.501 & 0.753 & 0.129 & 89.4 & 0.504 \\
\hline & & & 444 & 0.627 & 0.881 & 0.130 & 90.1 & 0.406 \\
\hline & & & 532 & 0.749 & 1.01 & 0.134 & 92.5 & 0.348 \\
\hline \multirow[t]{3}{*}{ Toluene } & D-type & 70 & 177 & 0.249 & 0.381 & 0.0676 & 46.8 & 0.528 \\
\hline & K-type & & & 0.247 & 0.410 & 0.0835 & 57.8 & 0.652 \\
\hline & P25 & & & 0.251 & 0.415 & 0.0840 & 58.1 & 0.656 \\
\hline \multirow[t]{3}{*}{ Formaldehyde } & D-type & 70 & 177 & 0.248 & 0.433 & 0.0947 & 65.6 & 0.740 \\
\hline & K-type & & & 0.247 & 0.390 & 0.0732 & 50.7 & 0.572 \\
\hline & $\mathrm{P} 25$ & & & 0.250 & 0.414 & 0.0840 & 58.1 & 0.656 \\
\hline
\end{tabular}




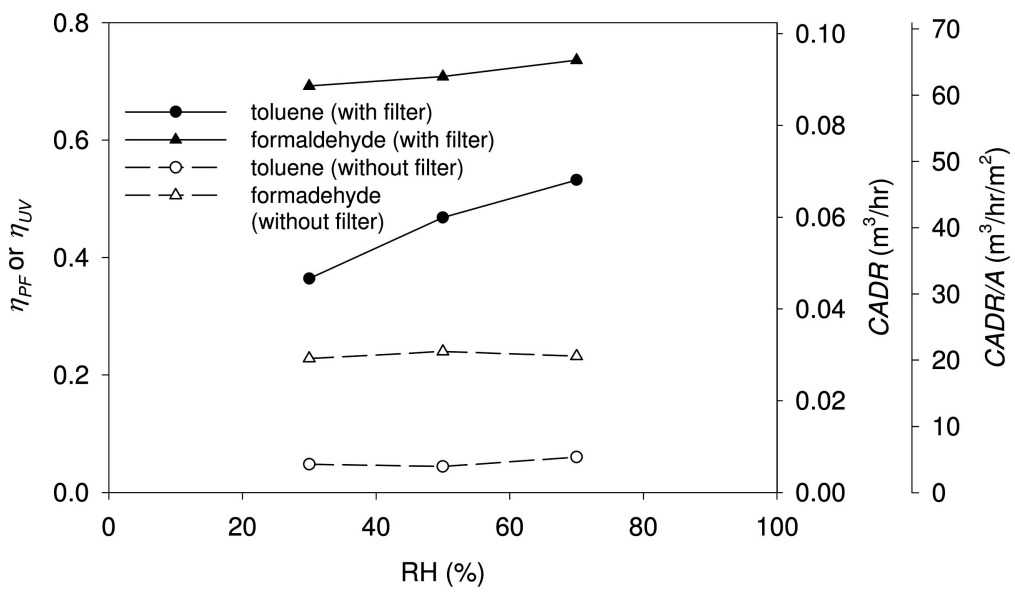

Figure 6. The relation between VOC removal efficiency with and without the photocatalytic filter ( $\eta_{P F}$ and $\eta_{U V}$ ) and RH, CADR and RH, and $\mathrm{CADR} / \mathrm{A}$ and $\mathrm{RH}$.

was weaker than that for removing toluene. This may result from the different hydrophilicities between formaldehyde and toluene and the competitive interaction between VOCs and water molecules for the adsorption site on the surface of a photocatalyst. In the presence of humidity, the surface of titania photocatalyts is hydroxylated, and hydroxyl groups are formed. A water molecule could be adsorbed on these hydroxyl groups via hydrogen bonding. By forming the $\mathrm{OH} \cdots \pi$ electron type interaction, toluene could also be adsorbed on the same hydroxyl groups. Because water and toluene are adsorbed on the same hydroxyl groups, there may be a competitive interaction between water and toluene adsorbed. Formaldehyde is more polar than toluene. Like water, formaldehyde is supposedly adsorbed on the hydroxyl groups on the surface of the photocatalyst via hydrogen bonding. 6,8 Thus, the competitive interaction between formaldehyde and water is probably stronger than that between toluene and water. The positive effect of $\mathrm{RH}$ on the $\mathrm{PCO}$ reaction rate by enhancing the formation of hydroxyl radical is partially counteracted by the negative effect of the competitive interaction between water and VOCs.

\section{Effect of Air Change Rate}

The Kns and the Kas of toluene with a photocatalytic filter present under different total air change rates are listed in Table 2 . The values of the $\eta_{\text {PF }}$ decrease with the increase of the face velocity, which is proportional to the total air change rate, as shown in Figure 7 . This result shows that the effectiveness of the photocatalytic filter to remove VOCs decreases with the total air change rate.

The $\mathrm{Kn}$ and the Ka of the toluene concentration without a photocatalytic filter present under different total air change rates are listed in Table 3 . The values of the $\eta_{U V}$ decrease with the increase of face velocity, as shown in Figure 7. The experimental results of different total air change rates for formaldehyde were similar to that for toluene.

Figure 7 demonstrates the relation between $\eta_{P F}$ and $v$ (face velocity), CADR and $v$, and CADR/A and $v$. The VOC removal efficiency of the photocatalytic filter, $\eta_{\mathrm{PF}}$, shows a linear negative relationship with face velocity within the face velocity range of $\sim 177-532 \mathrm{~m} / \mathrm{hr}$. According to
Figure 7 , the regression of $\eta_{\mathrm{PF}}$ for toluene and formaldehyde on the face velocity $(v)$ can be presented as the following equations:

$$
\begin{aligned}
\eta_{\mathrm{PF}}(\text { dimensionless })= & -0.000771(\mathrm{hr} / \mathrm{m}) \times v(\mathrm{~m} / \mathrm{hr}) \\
& +0.67(\text { for toluene })
\end{aligned}
$$

$$
\begin{aligned}
\eta_{\mathrm{PF}}(\text { dimensionless })= & -0.00112(\mathrm{hr} / \mathrm{m}) \times v(\mathrm{~m} / \mathrm{hr}) \\
& +0.919(\text { for formaldehyde })
\end{aligned}
$$

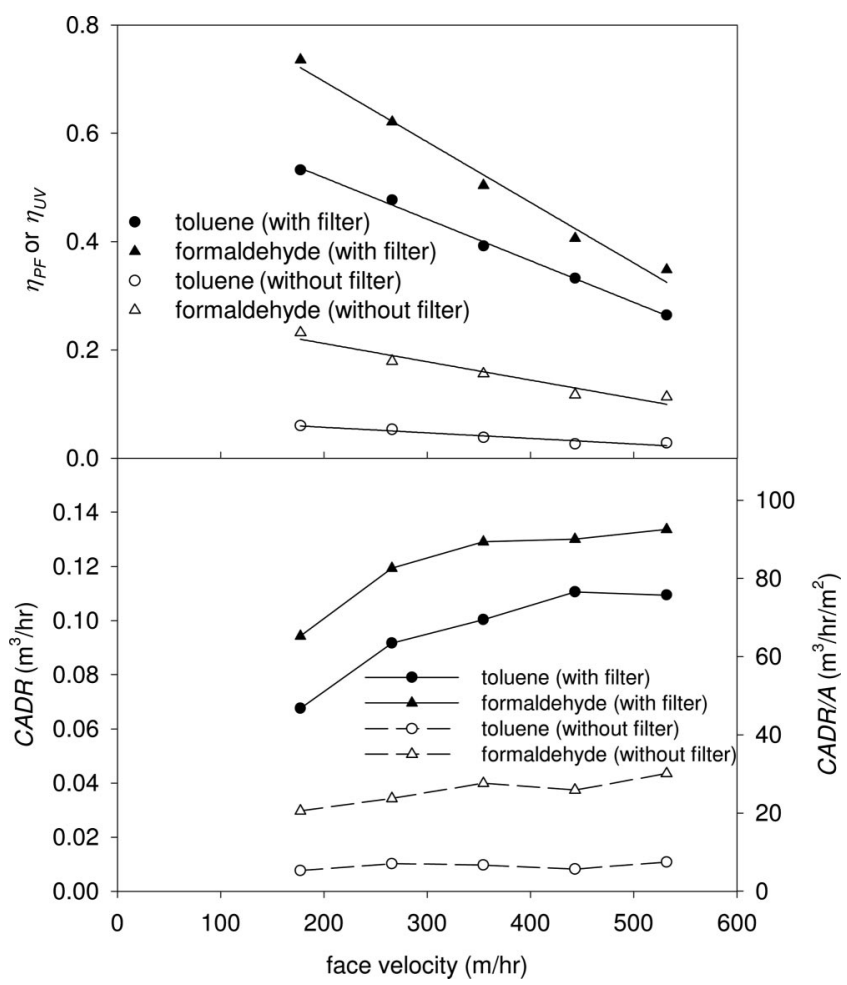

Figure 7. (a) Relation between VOC removal efficiency with and without photocatalytic filter ( $\eta_{\mathrm{PF}}$ and $\eta_{\mathrm{UV}}$ ) and face velocity $(v)$; (b) Relation between CADR and $v$ and CADR/A and $v$. 
Table 3. Summary of the experimental conditions, results, and calculated parameters.

\begin{tabular}{|c|c|c|c|c|c|c|c|c|}
\hline VOC & Filter & $\begin{array}{l}\text { RH } \\
\text { (\%) }\end{array}$ & $\begin{array}{c}V \\
(\mathrm{~m} / \mathrm{hr})\end{array}$ & $\begin{array}{c}\text { Kn } \\
\left(h^{-1}\right)\end{array}$ & $\begin{array}{c}\mathrm{Ka} \\
\left(\mathrm{hr}^{-1}\right)\end{array}$ & $\begin{array}{c}\text { CADR } \\
\left(\mathrm{m}^{3} / \mathrm{hr}\right)\end{array}$ & $\begin{array}{c}\text { CADR/A } \\
\left(\mathrm{m}^{3} / \mathrm{hr} / \mathrm{m}^{2}\right)\end{array}$ & $\eta_{u v}$ \\
\hline \multirow{3}{*}{ Toluene } & None & 30 & 177 & 0.249 & 0.261 & 0.0061 & 4.25 & 0.048 \\
\hline & & 50 & & 0.249 & 0.260 & 0.0056 & 3.90 & 0.044 \\
\hline & & 70 & & 0.248 & 0.263 & 0.0077 & 5.32 & 0.060 \\
\hline \multirow[t]{3}{*}{ Formaldehyde } & None & 30 & 177 & 0.247 & 0.304 & 0.0292 & 20.2 & 0.228 \\
\hline & & 50 & & 0.247 & 0.307 & 0.0307 & 21.3 & 0.240 \\
\hline & & 70 & & 0.248 & 0.306 & 0.0297 & 20.6 & 0.232 \\
\hline \multirow[t]{5}{*}{ Toluene } & None & 70 & 177 & 0.248 & 0.263 & 0.0077 & 5.32 & 0.060 \\
\hline & & & 266 & 0.374 & 0.394 & 0.0102 & 7.09 & 0.053 \\
\hline & & & 355 & 0.498 & 0.517 & 0.0097 & 6.74 & 0.038 \\
\hline & & & 444 & 0.627 & 0.643 & 0.0082 & 5.67 & 0.026 \\
\hline & & & 532 & 0.749 & 0.77 & 0.0108 & 7.45 & 0.028 \\
\hline \multirow[t]{5}{*}{ Formaldehyde } & None & 70 & 177 & 0.248 & 0.306 & 0.0297 & 20.6 & 0.232 \\
\hline & & & 266 & 0.375 & 0.442 & 0.0343 & 23.8 & 0.179 \\
\hline & & & 355 & 0.500 & 0.578 & 0.0399 & 27.7 & 0.156 \\
\hline & & & 444 & 0.627 & 0.7 & 0.0374 & 25.9 & 0.117 \\
\hline & & & 532 & 0.748 & 0.833 & 0.0435 & 30.1 & 0.113 \\
\hline
\end{tabular}

To convert the unit of $v(\mathrm{~m} / \mathrm{hr})$ into a dimensionless unit, the unit of the coefficient was set in front of the $v$ as hr/m. Substituting eqs 9 and 10 into eq 8 , respectively, we have:

$$
\begin{aligned}
\frac{\text { CADR }}{A}= & R_{\mathrm{r}} \times v[-0.000771(\mathrm{hr} / \mathrm{m}) \times v(\mathrm{~m} / \mathrm{hr}) \\
& +0.67] \text { (for toluene) }
\end{aligned}
$$

and

$$
\begin{aligned}
\frac{\mathrm{CADR}}{A}= & R_{\mathrm{r}} \times v[-0.00112(\mathrm{hr} / \mathrm{m}) \times v(\mathrm{~m} / \mathrm{hr}) \\
& +0.919](\text { for formaldehyde })
\end{aligned}
$$

The PCO reaction rate in this study can be defined as:

$$
r=\left(C_{\mathrm{up}}-C_{\mathrm{down}}\right) Q / A=C_{\mathrm{up}} \eta_{\mathrm{PF}} v=R_{\mathrm{r}} C \eta_{\mathrm{PF}} v
$$

which is very similar to CADR/A (See eq 8). Therefore, $\mathrm{CADR} / \mathrm{A}$ can be considered as a kind of PCO reaction rate independent of VOC concentration. As shown in Figure 7 and eqs 11 and 12, CADR/A is a function of face velocity. In heterogeneous catalytic reaction, the apparent reaction rate is dependant on the gas-phase mass-transfer rate (increases with face velocity), surface reaction rate (independent of face velocity), or both of them. The effect of gas-phase mass transfer from the bulk phase to the surface of photocatalytic filter decreased with face velocity increasing. When the face velocity is $>444 \mathrm{~m} / \mathrm{hr}$, the effect of mass transfer is no longer important.

The face velocities used in these experiments are lower than those in typical HVAC systems. The Reynolds numbers calculated from the configuration of the experimental system range from 51.4 to 154.6, which are smaller than those of typical HVAC systems (>2100). Therefore, the experimental system of this study is under a laminar flow condition, and typical HVAC systems are under a turbulent flow condition. The gas-phase masstransfer rates in typical HVAC systems are faster than those in this experimental system. Because the CADR/A asymptotically reaches the upper limit at face velocity of $444 \mathrm{~m} / \mathrm{hr}$, and this value corresponds with the real surface reaction rate, the CADR/A in typical HVAC systems remains as expected.

\section{Effect of Different Types of Photocatalytic Filters}

The Kn and the Ka of the toluene concentration in the chamber equipped with D-type, K-type, and Degussa P25 photocatalytic filters are shown in Table 2 . The effectiveness of the Degussa P25 photocatalytic filter for removing toluene was the best among the three photocatalytic filters tested, and the next was the K-type photocatalytic filter. The values of CADR, CADR/A, and $\eta_{\mathrm{PF}}$ of the three photocatalytic filters ranged from 0.0676 to $0.084 \mathrm{~m}^{3} / \mathrm{hr}$, 46.8 to $58.1 \mathrm{~m}^{3} / \mathrm{hr}$ per $\mathrm{m}^{2}$, and 0.528 to $0.659 \mathrm{~m}^{3} / \mathrm{hr}$, respectively.

The Kn and the Ka of the formaldehyde concentration in the chamber equipped with D-type, K-type, and Degussa P25 photocatalytic filters are listed in Table 2. The effectiveness of the D-type photocatalytic filter to remove formaldehyde was the best, and the next was the Degussa P25 photocatalytic filter. The values of CADR, CADR/A, and $\eta_{\mathrm{PF}}$ of the three photocatalytic filters tested ranged from 0.0732 to $0.0947 \mathrm{~m}^{3} / \mathrm{hr}, 50.7$ to $65.6 \mathrm{~m}^{3} / \mathrm{hr}$ per $\mathrm{m}^{2}$, and 0.572 to $0.74 \mathrm{~m}^{3} / \mathrm{hr}$, respectively. The VOC removal efficiency $\left(\eta_{\mathrm{PF}}\right), \mathrm{CADR}$, and CADR/A of the photocatalytic filters vary with the filter types, and the relevant mechanism needs further research.

\section{CONCLUSIONS}

According to the experimental results, photocatalytic filters are capable of controlling VOC contaminations in HVAC systems. The Kns of VOCs are dependent on the total air change rates, whereas the Kas are affected by air change rates (face velocity), $\mathrm{RH}$, and photocatalytic filter types. The VOC removal efficiency of the photocatalytic 
filters increases with RH but decreases with filtration face velocity. However, the CADR increases with face velocity and reaches the upper limit at a face velocity of $444 \mathrm{~m} / \mathrm{hr}$. CADR/A of the photocatalytic filter can be used to upscale the system, because this value corresponds with the real surface reaction rate when face velocity is $>444 \mathrm{~m} / \mathrm{hr}$. The effectiveness of the photocatalytic filters to control VOCs varies with filter types, and the relevant mechanism needs further research.

\section{ACKNOWLEDGMENTS}

The authors thank National Science Council of Republic of China for funding the research project of contract 93-EPA-Z-002-007.

\section{REFERENCES}

1. Bluyssen, P.M.; Coxa, C.; Seppänen, O.; Eduardo, de O. F.; Geo, C.; Müller, B.; Roulet, C-A. Why, When and How Do HVAC-Systems Pollute the Indoor Environment and What to Do About It? The European AIRLESS Project; Build. Environ. 2003, 38, 209-225.

2. Schleibinger, H.; Rüden, H. Air Filters from HVAC Systems as Possible Source of Volatile Organic Compounds (voc)-Laboratory and Field Assays; Atmos. Environ. 1999, 33, 4571-4577.

3. Kemp, S.J.; Kuehn, T.H.; Pui, D.Y.H.; Vesley D.; Streifel A.J. Filter Collection Efficiency and Growth of Microorganisms on Filters Loaded with Outdoor Air; ASHRAE Transact. 1995, 101, 228-238.

4. Pasanen, A-L.; Nikulin, M.; Berg, S.; Hintikka, E.L. Stachybotrys Atra Chorda May Produce Mycotoxins in Humid Environments; Am. Ind. Hygiene Assoc. J. 1994, 55, 62-65.

5. Alberici, R.M.; Jardim, W.F. Photocatalytic Destruction of VOCs in the Gas-Phase Using Titanium Dioxide; Appl. Cat. B: Environ. 1997, 14, 58-68.

6. Obee, T.; Brown, R.T. $\mathrm{TiO}_{2}$ Photocatalysis for Indoor Air Applications: Effects of Humidity and Trace Contaminant Levels on the Oxidation Rates of Formaldehyde, Toluene, and 1,3-Butadiene; Environ. Sci. Technol. 1995, 29, 1223-1231.

7. Kim, S.B.; Sung, C.H. Kinetic Study for Photocatalytic Degradation of Volatile Organic Compounds in Air Using Thin Film $\mathrm{TiO}_{2}$ Photocatalyst; Appl. Cat. B: Environ. 2002, 35, 305-315.

8. Sattler, L.M.; Lijiestrand, H.M. Method for Predicting Photocatalytic Oxidation Rates of Organic Compounds; J. Air \& Waste Manage. Assoc. 2003, 53, 3-12.

9. Wang, K.; Tsai, H.; Hsieh, Y. The Kinetics of Photocatalytic Degradation of Trichloroethylene in Gas Phase over $\mathrm{TiO}_{2}$ Supported on Glass Bead; Appl. Cat. B: Environ. 1998, 17, 313-320.

10. Matsunaga, T.; Tomoda, R.; Nakajima, T.; Nakamura, N.; Komine, T. Continuous- Sterilization System That Uses Photosemiconductor Powders; Appl. Environ. Microbiol. 1988, 54, 1330-1333.

11. Sunada, K.; Kikuchi, Y.; Hashimoto, K.; Fujishima, A; Bactericidial and Detoxification Effects of $\mathrm{TiO}_{2}$ Thin Film Photocatalysts; Environ. Sci. Technol. 1998, 32, 726-728.

12. Hall, R.J.; Sangiovanni, J.J.; Hollick, H.H.; Obee, T.N.; Hay, S.O. Design of Air Purifiers for Aircraft Passenger Cabins Based on Photocatalytic Oxidation Technology. In Air Quality and Comfort in Airliner Cabins. Nagda, N.L., Ed.; ASTM STP 1393; ASTM: West Conshohocken, PA, 2000 .
13. Andersen, I.; Lundqvist, G.R;. Molhave, L. Human Response to Controlled Levels of Toluene in Six-Hour Exposures; Scand. J. Work Environ. Health. 1983, 9, 405-418.

14. Baelum, J.; Andersen, I.; Lundqvist, G.R. Response of Solvent-Exposed Printers and Unexposed Controls to Six-Hour Toluene Exposure; Scand. J. Work Environ. Health. 1985, 11, 271-280.

15. Echeverria, D.; Fine, L.; Langolf, G.; Schork, A.; Sampaio, C. Acute Neurobehavioral Effects of Toluene; Br. J. Ind. Med. 1989, 46, 483-495.

16. Lambert, W. E.; Samet, J. M. Indoor Air Pollution. Chapter 48. In Occupational and Environmental Respiratory Disease; Harber P.; Schenker M.B.; Balmes J.R., Eds.; Mosby-Year Book, Inc.: St. Louis, MO, 1996; pp 784-807.

17. Morgan, K.T. A Brief Review of Formaldehyde Carcinorgenesis in Relation to Rat Nasal Pathology and Human Health Risk Assessment; Toxicol. Pathol. 1997, 25, 291-307.

18. Jones, A.P. Indoor Air Quality and Health; Atmos. Environ. 1999, 33, 4535-4564.

19. Ulsamer, A.G.; Gupta, K.C.; Cohn, M.S.; Preuss P.W. Formaldehyde in Indoor Air: Toxicity and Risk. In: Proceeding 75th Annual Meeting of Air Pollution and Control Association, Air Pollution and Control Association: New Orleans, LA 1982; p 16.

20. VanOsdell, D.W. Evaluation of Test Methods for Determining the Effectiveness and Capacity of Gas-Phase Air Filtration Equipment for Indoor Air Applications-Phase I: Literature Review and Test Recommendations; ASHRAE Trans. 1994, 100, 511-523.

21. Mattews, R.W. Photooxidative Degradation of Coloured Organics in Water Using Supported Catalysts. $\mathrm{TiO}_{2}$ on Sand; Water Res. 1991, 25, 1169-1176.

22. Hussain, A-E.; Serpone, N. Kinetic Studies in Heterogeneous Photocatalysis. 1. Photocatalytic Degradatlon of Chlorinated Phenols in Aerated Aqueous Solutions over $\mathrm{TiO}_{2}$ Supported on a Glass Matrix; J. Phys. Chem. 1988, 92, 5726-5731.

23. Salinaro, A.; Serpone, N.; Emeline, A.; Ryabchuk, V.; Hidaka, H. Relative Photonic Efficiencies and Quantum Yields in Heterogeneous Photocatalysis. Part II: Experimental Determination of Quantum Yields; Pure Appl. Chem. 1999, 71, 321-335.

24. Shang, J.; Du, Y.; Xu, Z. Photocatalytic Oxidation of Heptane in the gas-Phase Over $\mathrm{TiO}_{2}$; Chemosphere 2002, 46, 93-99.

25. Zhang, Y.; Yang, R.; Zhao, R.A. Model for Analyzing the Performance of Photocatalytic Air Cleaner in Removing Volatile Organic Compounds; Atmos. Environ. 2003, 37, 3395-3399.

\section{About the Authors}

Kuo-Pin Yu, Wei-Ming Huang, Shinhao Yang, and ChihCheng Wu are Ph.D. candidates, Chia-ling Lou is a Ph.D. student, and Grace W. M. Lee is a professor at the Graduate Institute of Environmental Engineering, National Taiwan University. Address correspondence to: Kuo-Pin Yu, National Taiwan University, No.71, Chou-shan Rd., Da-an District, Taipei City 106, Taiwan, R.O.C.; phone: +886223661544; fax: +886-2236615; e-mail: f89541105@ ntu.edu.tw. 
Copyright of Journal of the Air \& Waste Management Association (1995) is the property of Air \& Waste Management Association and its content may not be copied or emailed to multiple sites or posted to a listserv without the copyright holder's express written permission. However, users may print, download, or email articles for individual use. 